\title{
Qualitative Differences in the Exploration of Upright and Upside-Down Faces in Four-Month-Old Infants: An Eye-Movement Study
}

\author{
Mathieu Gallay; Jean-Yves Baudouin; Karine Durand \& Christelle Lemoine and Roger Lécuyer
}

Four-month-old infants were habituated with an upright or an upside-down face. Eye-movement recordings showed that the upright and upside-down faces were not explored the same way. Infants spent more time exploring internal features, mainly in the region of the nose and mouth, when the face was upright. They also alternated as frequently between the face's internal features (eyes vs. nose/mouth) as between external and internal features. When the face was upside down, the infants spent half of their time exploring external features, and preferentially alternated between external features and internal features. The main effect of inversion was a decrease of the looking time to the nose/mouth region and of the number of shifts between the eye region and the nose/mouth region

For some time now, scientific literature has considered the human face to be a specific object, leading some authors to propose that adults are experts in face processing (e.g., Diamond \& Carey, 1986). It has been suggested, moreover, that the explanation for this expertise might have to do with the type ofinformation adults use to recognize a face (see Diamond \& Carey, 1986; Maurer, Le Grand, \&Mondloch, 2002). In standard presentation conditions (upright faces), two types of information can be extracted from a face: componential information (obtained by way of local or analytic processing) and relational information (obtained by way of configural, holistic, or global processing). Componential information pertains to physical properties like the shape, texture, and color of the different elements of the face. Relational information pertains to the relative positions of the different elements (first-order relations: there are constant properties of human faces, such as the eyes being above the nose, itself above the mouth, and so forth) and to the distance between those elements (second-order relations; see Maurer et al., 2002). Several phenomena observed in adults have shown that configural information playsa crucial role in the high face-processing abilities of humans (for reviews, see Farah, Wilson, Drain, \&Tanaka, 1998; Maurer et al., 2002). In particular,many studies reported a stronger inversion effect in face processing than in object processing (e.g., Yin, 1969; for a review, see Valentine, 1988). This observation was interpreted as resulting from the inability to process configural information in upside-down faces.

What about infants? Are they able to process facesconfigurally? There is considerable evidence of an ability to recognize faces in the hours or days following birth, especially the mother's face (Bushnell,2001; Bushnell, Sai, \& Mullin, 1989; Field, Cohen, Garcia, \& Greenberg, 1984; Walton, Bower, \& Bower, 1992), but also newly familiar faces (Pascalis\& de Schonen, 1994). This ability is limited, however. Infants need both internal and external features to recognize their mother during the 1st month of life. They become able to recognize her from internal features alone at around 5 weeks, and from external features alone starting from the age of 4 months (Bartrip, Morton, \& de Schonen, 2001; Pascalis, de Schonen, Morton, Deruelle, \& Fabre-Grenet, 1995). They fail to recognize their mother from her profile alone before 2 months (Sai“ \& Bushnell, 1988), but are able to recognize other kinds of faces through various expressions and poses at around $3-6$ months (Pascalis, de Haan, Nelson, \& de Schonen, 1998).There is also some evidence that infants processinternal features early.Salapatek (1975) reported that 2-month-olds scanned internal features, notably the eyes and the mouth. One-month-olds mainly concentrated on external features (chin and hairstyle).More recently, Hunnius and Geuze (2004) reportedthat 6- to 26-week- 
old infants spent more than half of the time on either the mouth or eye region of their mother's face when she was looking, smiling, and nodding at them. A preference for attractive faces in 2- or 3-month-old infants (Langlois et al., 1987) or in newborns (Slater et al., 1998) further indicates that infants at these ages attend to internal features. They are also sensitive to changes in the componential properties of these internal features very early in development. For example, they can discrimination,local changes in schematic facial stimuli in the hours following their birth (Simion, Farroni, Macchi Cassia, Turati, \&DallaBarba, 2002; Turati\&Simion, 2002). They can also discriminate open versus closed eyes (Batky, Baron-Cohen, Wheelwright, Connellan, \&Ahluwalia, 2000).

There is also early evidence of configuralprocessing of facial information by infants. They can discriminate faces on the basis of configural changes by the age of 4 months (Deruelle\& de Schonen, 1998; for the same observation with 7-month-olds, see also Thompson, Madrid, Westbrook, \& Johnston, 2001). Six-month-old infants can also discriminate upright thatcherized faces (eyes and mouth reversed on the face) from nonthatcherized ones, even though only relational aspects of the features differentiate the two kinds of faces (Bertin\& Bhatt, 2004). Cashon and Cohen (2003) reported that 4-monthold infants look longer at a "switched" face made up of the internal features of a familiar face and the external features of another familiar face than at each whole familiar face. This result was interpreted as indicating that infants process the configuration made up of internal and external features. Cashon and Cohen (2003; see also Cohen \&Cashon, 2001) even described an $\mathrm{N}$-shaped pattern of development for upright faces, with the reaction to switched face emerging around 4 months, disappearing around 6 months, and emerging again around 7 months. Schwarzer and Zauner(2003) extended Cashon and Cohen's observation(2003; Cohen \&Cashon, 2001) to 8-month-old infants by switching single features rather than all internal features; infants reacted when only the eyes, nose, or mouth of a familiar face were put into another familiar face.

Seven months was the age at which the result pattern differed for the first time for upright and upside-down faces in the study by Cashon and Cohen (2003): infants did not look longer at the switswitchedface when it was upside down from this age on.Before that, the authors described a reaction forswitched upside-down faces at around 4 or 5 monthsbut neither before nor afterFthat was similar tothe reaction reported for upright faces. Nevertheless, there are also some observations that suggest thatinfants process upright and upside-down faces in adifferent way at an earlier age than that reported inthe study by Cashon and Cohen (2003). For example,newborns looked longer at attractive faces when theface was upright, but this preference disappearedwhen the faces were upside down (Slater, Quinn, Hayes, \& Brown, 2000). In 3- to 4-month-olds, Quinn,Yahr, Kuhn, Slater, and Pascalis (2002) observed apreference toward female faces that is abolishedwhen the faces are presented upside down. Turati,Sangrigoli, Ruel, and de Schonen (2004) studied theinfluence of face orientation on face recognition: theyhabituated and tested 4-month-old infants with eitherupright or upside-down faces. In their first experiment,infants recognized the familiar face (i.e.,they preferred a new face) whether upright or upsidedown when the point of view was not varied. In asecond experiment, however, they recognized a facefamiliarized from various points of view and shownon the test from a new point of view, only when itwas presented upright. Thus, infants processed uprightand upside-down faces differently; theprocessing they used for upright facesFbut not thatused for upside-down facesFallowed them to recognizefaces across various viewpoints. The deteriorationof this 
ability after inversion stronglysuggests that this ability relies on the processing ofconfigural information.

The way infants process upright faces allows themto extract a more stable representation of the face,and, consequently, its subsequent recognition is facilitateddespite variations such as a change inviewpoint. The fact that this ability was no longerreported for upside-down faces further suggests thatthe mechanism subtending upright face processinghas to do with configural information. One way ofunderstanding the difference in the processing ofupright and upside-down faces is to study how infantsexplore both types of faces. This can be done byway of an eye-movement study: knowing how infantslook at faces can tell us about the kind ofprocessing they implement for each orientation (seeHaith, 2004; Johnson, Slemmer, \&Amso, 2004). Thepurpose of the present study is to find out if 4-monthold infants process upright and upside-downfaces in the same way, by recording eye movementsduring a habituation phase. Different processingmodes for upright and upsidedown faces shouldgive rise to an exploration pattern that is qualitatively different (how infants explore a face), if notquantitatively different (how long infants explore aface). In other words, even if infants spend the sameamount of time exploring upright and upsidedownfaces and, as a consequence, if traditional measuresdo not allow evidencing differences in the processingof faces under the two orientations (e.g., Experiment 1 in the study by Turati et al., 2004, see also Cashon\&Cohen, 2003), infants may pay attention to differentparts of the face under the two orientations, and theway they explore these facial parts may differ.To test these hypotheses, we used an eye-trackingsystem at the same time as we recorded lookingtimes by means of a classical manual method. Theeye-tracking system was expected to enable us notonly to record the same quantitative indicators as inthe classical manual method (i.e., amount of stimulusexploration time) but also to see whether therewere any qualitative differences between the variousexperimental conditions by determining whetherinfants looked at the same features in the same order.

\section{Experiment}

\section{Method}

\section{Participants}

Forty-four 4-month-old Caucasian infants (27 girlsand 17 boys, M5118.67 days, SD54.23) were tested.They were healthy and had no known medicalproblems. Parents were contacted by mail andphone, and all gave their written consent. Twentyinfants were not included in the final sample becauseof fussing or crying, or because of technical problemsduring the experiment. The final sample containedtwenty-four 112- to 128-day-old infants (16 girls and8 boys, M5119.33, SD54.18).

\section{Material}

Photographs of two brown-eyed females (21 and27 years old) were used. The photograph dimensionswere 565 _ 565 pixels, which corresponded to a faceof approximately $28 \mathrm{~cm}$ (i.e., 29.51 of visual angle) inheight once on the screen. The experimental apparatuswas composed of two computers, three controlscreens, a presentation monitor $(70 \mathrm{~cm}$ flat screen), and an eye-tracking system developed by ASL(model R6). This system included a remote optics eyecamera that allowed the infant approximately onesquare foot of head movement and eliminated theneed for head restraint. The camera was placed infront of the 
infant, below the monitor, at a distance ofapproximately $50 \mathrm{~cm}$. The infant's line of gaze was measured by computing the pupil-corneal reflectionat a sampling rate of $50 \mathrm{~Hz}$. The accuracy level wasabout 0.51 of visual angle, and the resolution wasabout 0.251 of visual angle.

\section{Procedure}

The experiment took place in a quiet room ofthe Henri Pieron Center at the Paris 5 University.The infants were seated in a car seat with the headbetween two pillows, in an experimental box facingthe monitor at a distance of $60 \mathrm{~cm}$ from its center.Once the infant was positioned, a curtain was drawnso that the only visual stimulations that could attracthis or her attention were the ones displayed on thescreen. The parents were present but were asked toremain quiet during the entire experiment. An experimenterwas behind the camera in the dark outsidethe experimental box, so as to face the infant. Hekept his hand on the computer mouse to control thepresentation time during habituation (the experimenterheld the mouse button down while the infantlooked at the screen and released it when the infantmoved his/her eyes away). We used a habituation paradigm. Each infant wastested in two experimental sessions: one with uprightfaces and one with upside-down faces. Theorder of the upright versus upside-down sessionswas alternated across infants. Each session includedtwo phases: calibration and habituation.Calibration. A clown was presented in the centerof the screen. When the infant started to look at it, theclown moved to the top left corner of the screen andremained in this position until the infant fixated it.Then, it moved to the bottom right corner and remainedin this position. These three positions wereused to compute the pupil-corneal reflection characteristicsfor three points on the screen. Thesecharacteristics were used to derive the gaze directionduring the habituation.

\section{Habituation.}

We used an infant-control procedure.A habituation face was displayed until the infantlooked in another direction for more than $1 \mathrm{~s}$.When the infant did not look the face for $15 \mathrm{~s}$, thenext trial was run. If she or he never looked elsewherefor $1 \mathrm{~s}$, the face was presented for a maximumof $15 \mathrm{~s}$. During all the habituation trials of a session,the infant saw exactly the same face in the sameorientation, with the same presentation criterion, until she or he was habituated. Cohen's (1972) habituationcriterion was used, that is, the infant wasconsidered to be habituated when the mean lookingtime for 3 consecutive trials was less than half themean looking time for the first 3 trials. The minimum number of trials was 6 . If the infant did not reach thiscriterion after 15 trials, the habituation was stopped.Between each trial, a blue screen was presented for $1 \mathrm{~s}$. The infants were first habituated with one photograph,in such a way that different infants performedthe habituation phase with the different photographs.During the second session, the infants werehabituated with a photograph of the other femaleunder the other orientation. The data were collectedboth by manual recording and by the eye-trackingsystem.

\section{Results}

Quantitative Data

Manual recording of gaze direction.

First, the totaltime spent exploring upright versus upside-downfaces across all trials, and the number of trialsneeded to reach the habituation criterion werecomputed. T tests were then performed to find outwhether there was a significant difference betweenupright and upsidedown faces. The total lookingtime across all trials was $61.6 \mathrm{~s}$ (SD535.2) for uprightfaces and 
$52.5 \mathrm{~s}$ (SD524.3) for upside-downfaces. The mean number of trials was 8.75 (SD53.05)for upright faces and 8.79 (SD52.95) for upsidedownfaces. Neither the total looking time nor thenumber of trials differed significantly between uprightand upside-down faces, $t(23) 51.10$ and, $t(23) 50.05$, respectively. For each infant, the total time spent looking at thescreen during the first three trials and during the last three trials was computed. The means for each experimentalcondition are presented in Table 1. Thesedata were input into a $2_{-} 6$ ANOVA with orientation(upright vs. upside-down) and trial (1 vs. 2 vs. 3 vs. _ 3 vs. _2 vs. _1) as withinsubject factors. Themain effect of trial was significant, $F(5,115) 575.78$, po.0001. Infants looked significantly longer at thescreen during the first three trials $(10.5,8.8$, and 8.2 $\mathrm{s}$, respectively) than during the last three trials $(4.5,3.8$, and $3.2 \mathrm{~s}$, respectively), $\mathrm{F}(1$, 23)5270.98, po.0001.

Table 1

Manual and Ocubonetric Recording of Duration and Pencentage of Looks During Habifuation

\begin{tabular}{|c|c|c|c|c|c|c|c|c|c|c|c|c|}
\hline \multirow[b]{2}{*}{ Orientation trial } & \multicolumn{6}{|c|}{ Upright } & \multicolumn{6}{|c|}{ Upside down } \\
\hline & 1 & 2 & 3 & -3 & -2 & -1 & 1 & 2 & 3 & -3 & -2 & -1 \\
\hline \multicolumn{13}{|c|}{ Marual racording $(N-24)$} \\
\hline In seconds & 10.9 & 8.7 & 8.4 & 5.0 & 3.8 & 3.2 & 10.0 & 8.8 & 8.0 & 4.0 & 3.8 & 3.2 \\
\hline$S E$ & 0.7 & 0.8 & 0.9 & 0.6 & 0.4 & 0.3 & 0.7 & 0.8 & 0.8 & 0.4 & 0.5 & 03 \\
\hline \multicolumn{13}{|c|}{ Quavtitative oculometric data $(N-21)$} \\
\hline \multicolumn{13}{|c|}{ Looking at the screen } \\
\hline In seconds & 11.1 & 8.0 & 7.8 & 53 & 3.7 & 3.6 & 10.3 & 7.7 & 6.8 & 4.3 & 3.6 & 4.1 \\
\hline$S E$ & 0.8 & 0.9 & 1.0 & 0.9 & 0.4 & 0.4 & 0.9 & 1.0 & 0.9 & 0.5 & 0.5 & 0.5 \\
\hline \multicolumn{13}{|c|}{ Looking at the face } \\
\hline In seconds & 10.6 & 7.4 & 7.1 & 4.9 & 3.4 & 3.2 & 9.3 & 7.0 & 5.9 & 3.7 & 3.0 & 35 \\
\hline$S E$ & 0.8 & 0.9 & 0.9 & 0.9 & 0.4 & 0.4 & 0.9 & 0.9 & 0.9 & 0.4 & 0.5 & 0.5 \\
\hline \multicolumn{13}{|c|}{ Qualita the oculomatric data $(N-21)$} \\
\hline \multicolumn{13}{|c|}{ Looking at internal features } \\
\hline In seconds & 7.7 & 55 & 4.9 & 3.2 & 2.2 & 21 & 5.3 & 35 & 33 & 1.7 & 1.6 & 21 \\
\hline$S E$ & 0.8 & 0.9 & 0.9 & 0.8 & 0.4 & 0.3 & 0.7 & 05 & 0.7 & 0.2 & 0.3 & 0.5 \\
\hline In $\%$ & 69.1 & 63.9 & 622 & 58.2 & 58.8 & 65.9 & 56.5 & 51.6 & 503 & 48.4 & 51.2 & 52.9 \\
\hline$S E$ & 4.6 & 6.1 & 5.7 & 6.0 & 6.0 & 6.8 & 4.6 & 4.4 & 5.8 & 53 & 5.9 & 70 \\
\hline \multicolumn{13}{|c|}{ Looking at the eye region } \\
\hline In seconds & 33 & 2.4 & 23 & 1.9 & 0.9 & 1.2 & 28 & 15 & 2.0 & 0.7 & 0.5 & 10 \\
\hline $\mathrm{SE}$ & 0.7 & 0.7 & 0.7 & 0.7 & 03 & 0.3 & 0.6 & 03 & 0.5 & 0.1 & 0.1 & 0.3 \\
\hline In $\%$ & 293 & 24.6 & 26.8 & 28.0 & 24.4 & 30.6 & 31.7 & 26.4 & 303 & 21.0 & 20.7 & 23.8 \\
\hline SE & 5.0 & 5.2 & 5.4 & 53 & 6.9 & 5.7 & 5.6 & 4.6 & 6.0 & 4.5 & 5.2 & 55 \\
\hline \multicolumn{13}{|c|}{ Looking at the nose/mouth region } \\
\hline In seconds & 3.9 & 2.8 & 21 & 1.0 & 1.0 & 0.8 & 1.6 & 13 & 0.9 & 0.5 & 0.8 & 0.8 \\
\hline $\mathrm{SE}$ & 0.8 & 0.6 & 0.5 & 0.3 & 0.3 & 0.2 & 0.3 & 0.4 & 0.2 & 0.1 & 0.3 & 0.2 \\
\hline In $\%$ & 34.5 & 34.5 & 26.9 & 24.5 & 28.4 & 28.1 & 15.9 & 15.0 & 133 & 14.6 & 222 & 213 \\
\hline $\mathrm{SE}$ & 55 & 5.1 & 4.9 & 6.1 & 5.7 & 5.8 & 25 & 3.6 & 1.9 & 33 & 4.3 & 55 \\
\hline
\end{tabular}




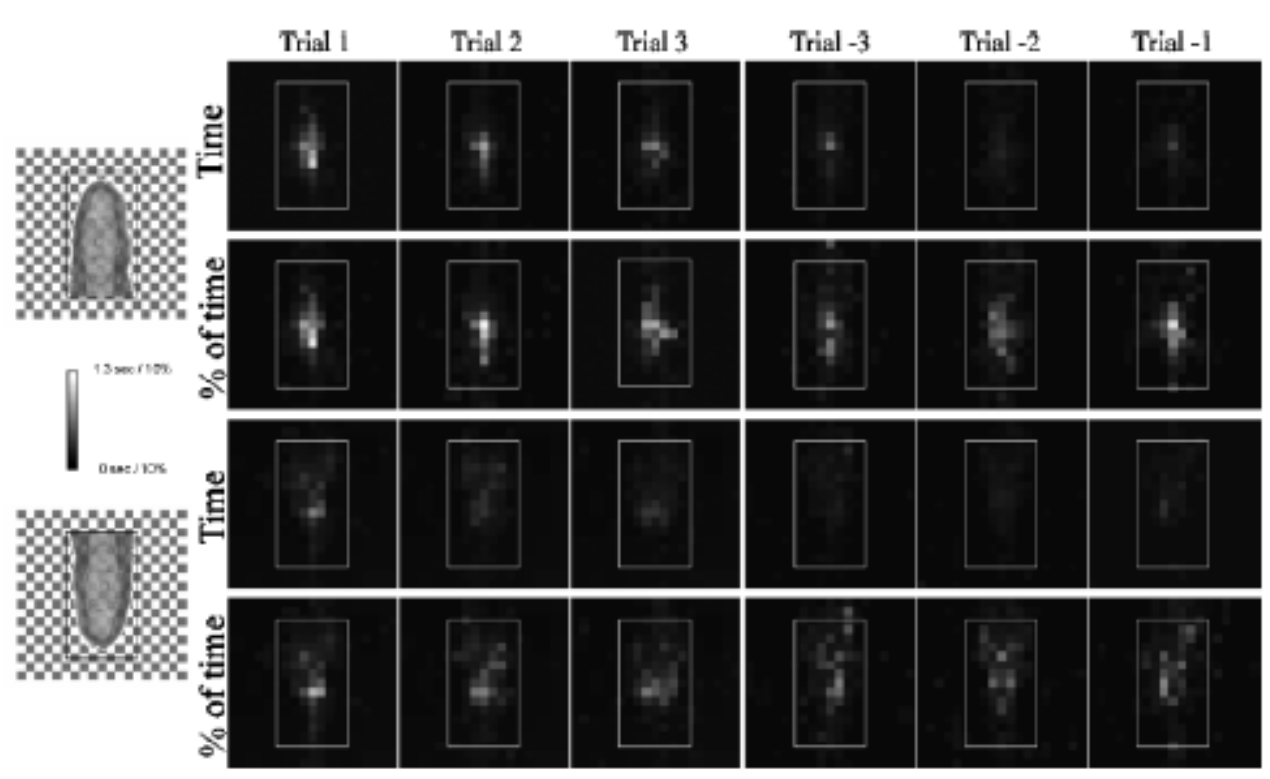

Figure 1. Time in milliseconds and percentage of time spent by infants in each of the 361 areas during habituation.

The main effect of orientation was nonsignificant, $F(1,23) 50.55$, as was the interaction between orientationand trial, $F(5,115) 50.39$.The manual recordings suggested that there wasno difference in habituation between the two faceorientations; the infants needed a similar number oftrials to reach the habituation criterion, and theyspent a similar amount of time exploring the screenfor both orientations and on all trials.Oculometric data: how long the infants explored theface. The data from three infants were not includedbecause of calibration problems. The oculometricdata were used first to collect similar quantitative measures as with manual recording. For this, wecomputed the total looking time for each trial andeach orientation. The correlation between totallooking time on each trial measured by the experimenterand by the oculometer for these 21 infantswas $r 5.84$, po.0001. The data limited to the infants'looks at the faces were also analyzed. For this, wecomputed the time each infant spent looking at thephotograph of the face (as illustrated in Figure 1)without considering the time she or he spent onother parts of the screen. Table 1 gives the meanlooking times for the screen and the face collectedwith the eye-tracking system. These data wereanalyzed by 2 _ 6 ANOVAs with orientation (uprightvs. upside-down) and trial (1 vs. 2 vs. 3 vs. _3vs. _2 vs. _1) as within-subject factors.As regards looking at the screen, the main effect oftrial was significant, $F(5,100) 538.18$, po.0001. Infantslooked significantly longer at the screen duringthe first three trials $(10.7,7.9$, and $7.3 \mathrm{~s}$, respectively)than during the last three $(4.8,3.6$, and $3.8 \mathrm{~s}$, respectively), $F(1,20) 5211.30$, po.0001. The main effectof orientation was nonsignificant, $F(1,20) 50.42$, as was the interaction between orientation and trial, $F(5,100) 50.57$. Concerning looking at the face, the

main effect of trial was also significant, $F(5,100) 536.79$, po.0001. Infants looked significantly longerat the face during the first three trials $(9.9,7.2$, and6.5 s, respectively) than during the last three $(4.3,3.2$, and $3.3 \mathrm{~s}$, respectively), $F(1,20) 5143.43$, po.0001. The main effect of orientation was nonsignificant, $F(1,20) 51.25$, as was the interaction betweenorientation and trial, $F(5,100) 50.76$. The quantitative oculometric data replicated themanual recording data by showing no effect of orientationon habituation. They also extended thisobservation to the cases in which the looks at otherparts of the screen than the face were removed from the analysis. Thus, the manual as well as the oculometricdata suggest that 4-month-old infants are notsensitive to face orientation and that they become 
habituated in the same way to upright and upsidedownfaces.

\section{Qualitative Data}

Oculometric data: how the infants explored the face.In order to find out whether the infants' explorationdiffered qualitatively across experimental
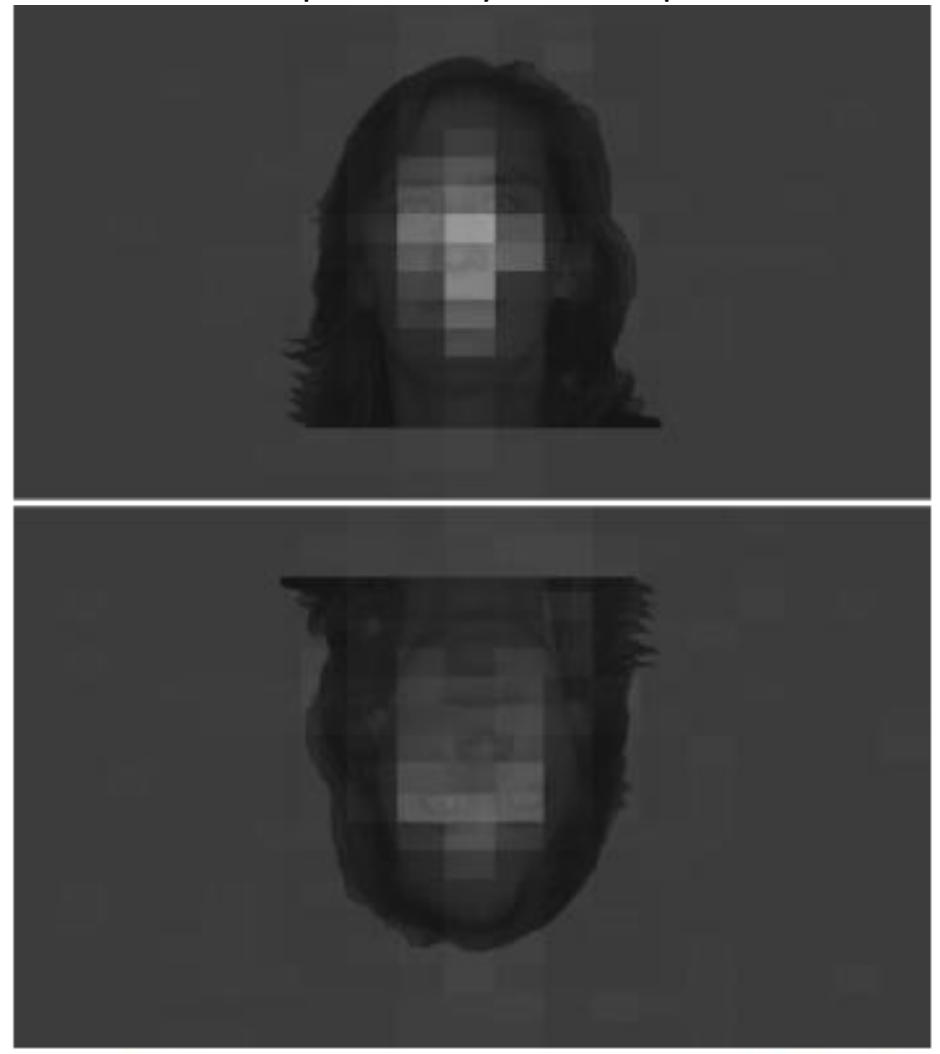

Figure 2. Mean percentage of time looking at each a rea for upright versus upside-down faces. The higher the area, the more the time the infants spent looking at it.

conditions, we defined a matrix of 361 areas (19 rowsby 19 columns) that covered the whole screen. Then,for each of the 21 infants, we computed (i) the timethe infant's gaze was in each area during a trial and(ii) the percentage of time she or he spent in each

area as compared with the time spent looking at thescreen. The total time and the percentage for eacharea were then averaged across all infants and alltrials. This procedure allowed us to visualize thepatterns of areas explored by the infants in each experimentalcondition. The patterns for the first threeand the last three trials in each orientation are presentedin Figure 1. The mean percentages in eacharea on these six trials are illustrated in Figure 2 forupright versus upside-down faces. Being able to seewhere (rather than how long) the infants looked allowedus to set forth and test hypotheses about infants'qualitative exploration of faces. The visual inspection of Figures 1 and 2 firstsupports the findings of the quantitative analyses. When we considered the time spent in the differentareas (first and third rows in Figure 1), it appearedthat the infants spent less and less time exploring theface as the number of trials increased. This decreasewas similar for both upright and upside-down faces.Qualitatively, the percentages of time spent in each 


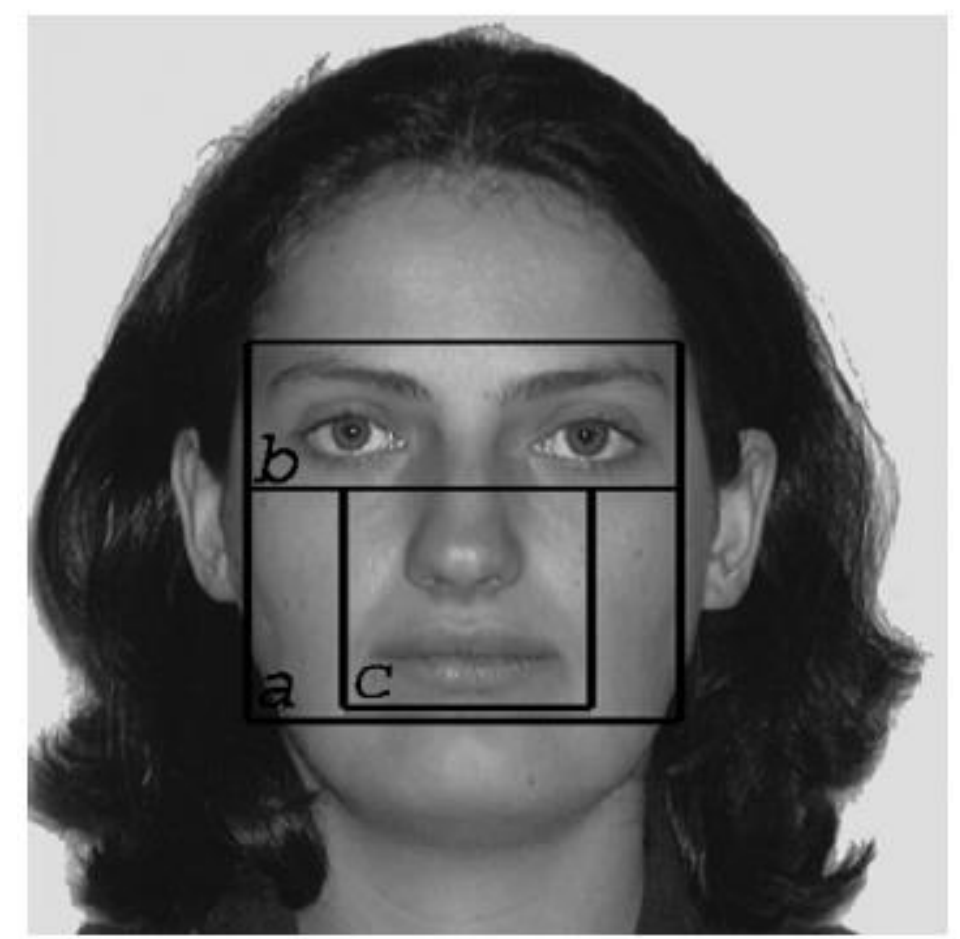

Figure3. Areas of interest: internal features (overall rectangle a), eye region (rectangle $b$ ), and nose/mouth region (rectangle $c$ ). Extemal features are the regions in the photograph other than

area indicate that the main areas of interest werethose corresponding to the face, and more preciselyto internal facial features (second and fourth rows inFigure 1; see also Figure 2). They also suggest thatthere were some qualitative differences in the exploration of upright versus upside-down faces; infantsseemed to spend more time looking at internalfeatures when the face was upright than when it wasupside down. Moreover, when they looked at internalfeatures, the infants seemed to focus on the eyeregion when the face was upside down, whereasthey seemed to focus on the regions of both the eyesand the nose/mouth when the face was upright.To test the hypothesis that exploration of somefacial features (internal features, eyes, nose/mouth)differs for upright and upside down faces, we defined three facial regions and then computed twoindexes for each infant and each trial: (i) the totaltime she or he spent exploring that region and (ii) thepercentage of time she or he spent in that regionduring face exploration (i.e., in the rectangular zonearound the face shown in Figure 1). An illustration ofthe three regions considered is presented in Figure 3.The sizes of the areas in term of visual angle were10.51 high by 13.91 wide for the internal feature region, 4.71 high by 13.91 wide for the eye region, and71 high by 7.91 wide for the nose/mouth region. Themean looking times and percentages for these threeregions are presented in Table 1. For some infants in certain conditions, the percentage could not be computed because they spent no time on the faceduring certain trials ( $2.4 \%$ of the data). We replacedthese data by the average of the mean percentage forother infants in that condition and the mean percentagefor each of those infants in other conditions.Then, the mean time and the mean percentage foreach region were analyzed in 2 _ 6 ANOVAs withorientation (upright vs. upside-down) and trial (1 vs. 2 vs. 3 vs._3 vs._2 vs._1) as within-subjectfactors. Exploration of internal features.

Concerning lookingtime at internal features, the main effect of orientation

was significant; infants looked longer at internalfeatures when the face was upright (4.3 vs. $2.9 \mathrm{~s}$ forupside-down faces), $\mathrm{F}(1,20) 57.98$, po.05. The maineffect of trial was also significant, 
$\mathrm{F}(5,100) 521.53$, po.0001; looking time decreased between thefirst and last trials $(6.5,4.5$, $4.1,2.5,1.9$, and $2.1 \mathrm{~s})$. The interaction between orientation and trial was

nonsignificant, $F(5,100) 51.84$. For the percentageof time spent looking at internal features, the maineffect of orientation was significant; infants spent agreater amount of time on internal features onupright faces $(63.0 \%$ vs. $51.8 \%$ for upside-downfaces), $F(1,20) 511.78$, po.01. Neither the maineffect of trial, $F(5,100) 50.87$, nor the interactionbetween orientation and trial, $F(5,100) 50.85$, weresignificant.Exploration of the eye region. For looking time at theeye region, the main effect of trial was significant, $F(5,100) 511.09$, po.0001; eye-looking time decreasedbetween the first and the last trials (3.0, 1.9,2.1, 1.3, 0.7 , and $1.1 \mathrm{~s})$. Neither the main effect oforientation, $F(1,20) 51.28$, nor the interaction betweenorientation and trial, $F(5,100) 50.75$, weresignificant. For the percentage of eyelooking time, the main effect of orientation, $F(1,20) 50.08$, themain effect of trial, $F(5$, 100)51.12, and the interactionbetween orientation and trial, $F(5,100) 50.73$, were all nonsignificant.

Exploration of the nose/mouth region.

For lookingtime at the nose/mouth region, the main effect oforientation was significant; infants looked longer atthe nose/mouth when the face was upright (1.9 vs.1.0 s for upsidedown faces), $F(1,20) 56.43$, po.05. The main effect of trial was also significant, $F(5$, 100)513.51, po.0001; looking time decreasedbetween the first and the last trials $(2.9,2.0$, $1.5,0.8,0.9$, and $0.8 \mathrm{~s})$. The interaction between orientationand trial was also significant, $\mathrm{F}(5$, 100)53.61, po.01. Linear comparisons indicated that the trial effect wassignificant for upright faces, $F(5,100) 59.80$, po.0001, and for upside-down faces, $F(5,100) 53.05$, po.05, but that the nose/mouth looking time decreasedfaster for upright faces. The orientation effectwas significant on the first trial, $3.9 \mathrm{~s}$ for upright facesvs. $1.6 \mathrm{~s}$ for upside-down faces, $F(1$, 20)56.33, po.05, the second trial, $2.8 \mathrm{~s}$ for upright faces vs. $1.3 \mathrm{~s}$ forupside-down faces, $F(1$, 20)54.51, po.05, and thethird trial, $2.1 \mathrm{~s}$ for upright faces vs. $0.9 \mathrm{~s}$ for upsidedownfaces, $F(1$, 20)54.92, po.05, but not on theother trials (all Fo3.70). For the percentage of time inthe nose/mouth region, the main effect of orientationwas significant; infants spent a greater amount oftime on the nose and mouth for upright faces $(29.5 \%$ vs. $17.1 \%$ for upside-down faces), $F(1,20) 58.02$, po.05. Neither the main effect of trial, $F(5,100) 50.97$, nor the interaction between orientation andtrial, $F(5,100) 51.16$, were significant.Qualitative analyses showed that, although thequantitative exploration of upright and upsidedownfaces was similar (i.e., infants spent the sameamount of time exploring the face), the two types offaces were not explored in the same way. For uprightfaces, infants mainly explored internal features (63\% of the face-exploration time), with a great amount oftime spent on the nose/mouth region (29.5\% of the face-exploration time, which corresponds to $46.8 \%$ of the time spent on internal features). For upsidedownfaces, infants spent less time on internal features(51.8\%), which means that they spent nearlyhalf of their time exploring external features. Theywere also less interested in the nose and mouth $(17.1 \%$ of the faceexploration time, which correspondsto $33.0 \%$ of the time spent on internal features).Thus, the main internal-feature area exploredin upside-down faces was the eyes. However, theinfants spent the same amount of time on the eyes asthey had done for upright faces.

Time course of the exploration. Qualitative analysesindicated that the infants did not look at the samefacial features for the two face orientations. Weanalyzed the time course of the exploration behaviorin order to find out whether different features wereexplored in a uniform way across infants. The percentageof infants looking at each of the five areas(nose/mouth region, eye region, other internal regions, external feature region, other; 
see Figure 3)was calculated at 20-ms intervals. The category "other" includes infants who no longer looked at thescreen. Changes in these percentages were consideredover a period of $10 \mathrm{~s}$ that started, for eachinfant, when she or he first looked at the face (rectangular area in Figure 1) for at least $100 \mathrm{~ms}$. Thetime course of these percentages for each trial and each orientation is presented in Figure $4 a$ and b,990 Gallay, Baudouin, Durand, Lemoine, and Lécuyerwhich can be read as follows: (i) If the face explorationpath is the same across infants, then one canexpect them to look at the same region at the sametime, with this region changing over time. In thiscase, oscillations should appear in Figure 4a and b. If, on the other hand, the exploration of the differentfeatures varies randomly across infants, no oscillationis expected because the infants' looks at thedifferent regions should be randomly distributedover time. (ii) In the case of oscillations, the differentperiods of oscillation are indicative of the explorationpath. If, for example, the majority of the infants lookedat the eyes during a specific period of time, and at thenose and mouth after that, then this should show upas an initial eye-exploration period, followed by a shiftto the nose and mouth at the transition between thetwo periods. For our 21 infants, we considered two percentages (at different times or for different regions)to be significantly different (using a $t$ test) at po. 05 fora difference above $19 \%$, at po. 01 for a differenceabove $33 \%$, at po.001 for a difference above $42 \%$, andat po.0001 for a difference above $57 \%$.Figure $4 a$ and $b$ appear to support the staticqualitative data; a greater proportion of the infantslooked at the nose/mouth region when the face wasupright rather than upside down, and at externalfeatures when the face was upside down rather thanupright. No particular difference is found for theeyes. Oscillations in the same time course also indicatedsome regularity in the exploration path. On thefirst trial, for example, most infants started to lookat external features, whatever the orientation of theface. A great number of them also looked atthe nose/mouth region. Approximately $500 \mathrm{~ms}$ afterthe beginning of the exploration, most infants gotto the eyes and remained there for 2,000-2,500 ms.
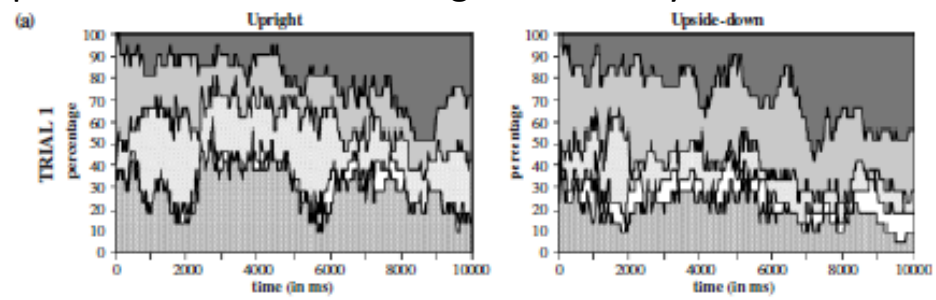

Uright

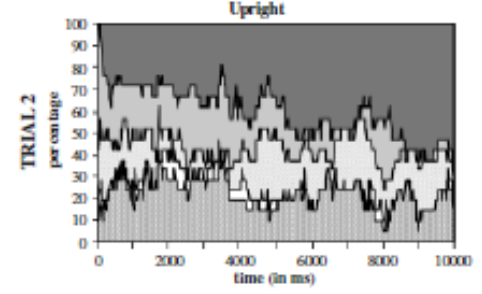

Upside-down
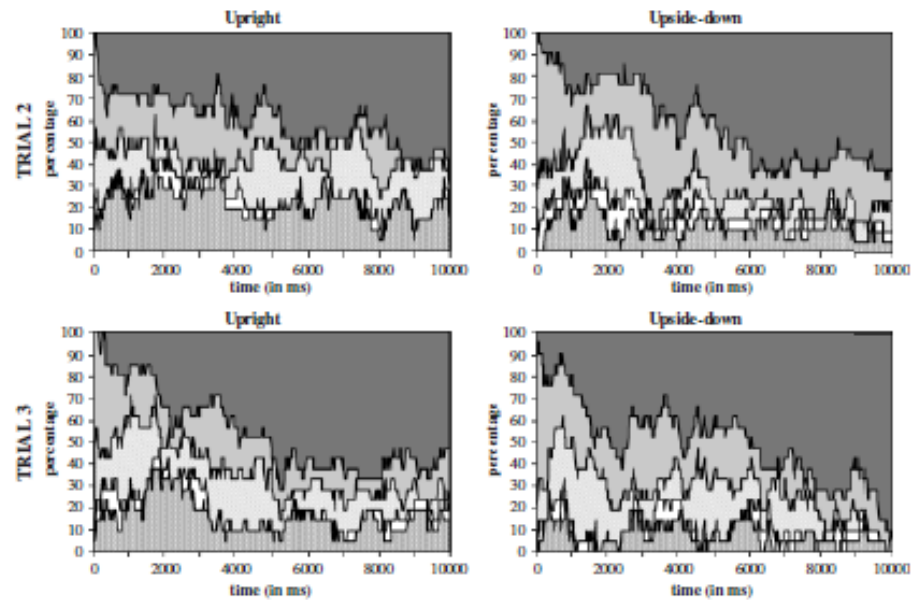

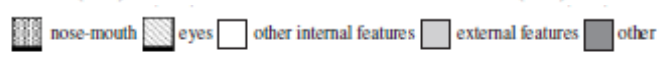


(b)

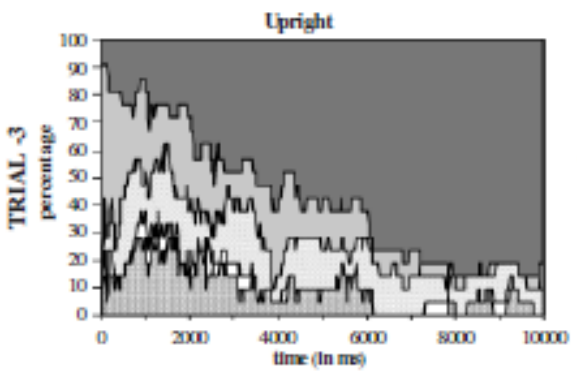

Upright
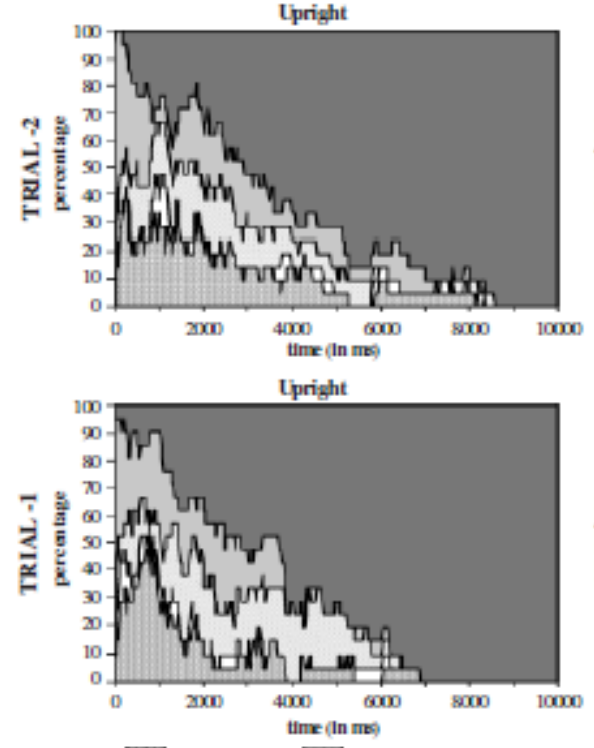

9 nose-mouth $\square$ eyes $\square$ other internal feature

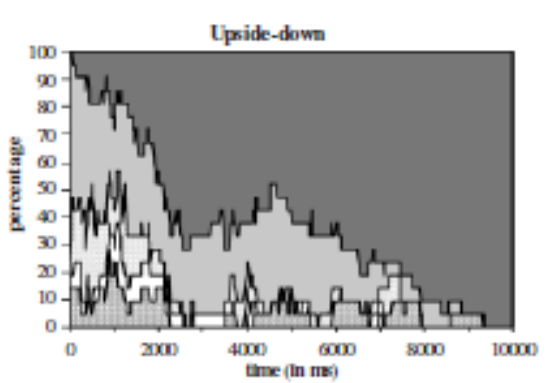

Upride-down

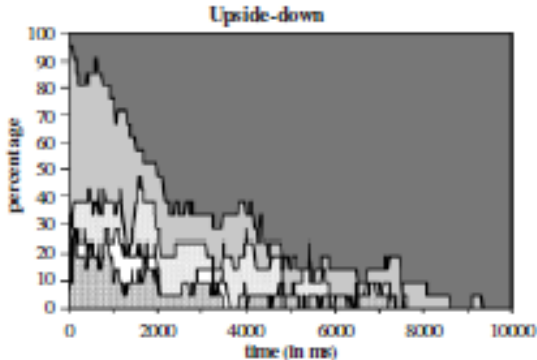

Upride-down

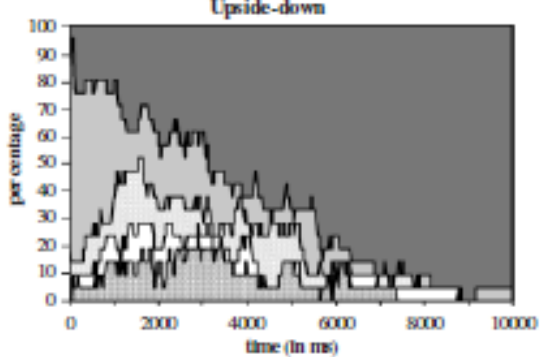

external features $\square$ other

The first difference between upright and upsidedownfaces showed up between 1,000 and $1,500 \mathrm{~ms}$; whereas some infants tended to go from the eyes tothe nose and then return to the eyes for upright faces, the pattern was not so apparent for upside-downones. The difference between upright and upsidedownfaces became clear-cut at 2,000-2,500 ms. For upright faces, most infants arrived at the nose/mouth region between 2,500 and 4,500 $5,000 \mathrm{~ms}$, and many of them looked at the eye region also.Later, an increase in eye-region looking showed upbetween 4,500 and $5,000 \mathrm{~ms}$, concurrent with a decreasein the percentage of infants who looked at thenose/mouth from there, suggesting that most infantswent from the nose/mouth to the eyes. At 6,000 ms, the percentage of infants looking at the nose/mouthincreased again, whereas the percentage of infantslooking at the eyes decreased. The percentage of infantswho looked at external features was quite lowand stable during these periods. For upside-downfaces, the main variation after 2,000 ms was in thepercentage of infants looking at external features, which was also greater than for upright faces.However, it is not clear whether the infants alternatedbetween external features and one specificregion, either the eyes or the nose/mouth. A similarpattern emerged to various extents on other trials, with many infants who looked at external featuresfirst, and then at the eyes during the first few seconds.Then, they alternated between the nose/mouth and eye regions for upright faces, with apredominance and variation of looks at externalfeatures for upside-down faces.Figure $4 a$ and $b$ thus indicated quite a congruentexploration path across infants, at least on thefirst trial, with different paths for upright andupside-down faces. Thus, there appears to be acommon rule about which features were explored,the order in which they were explored, and themoment the infant switched from one to the other.The apparent lack of variation during certain periods(e.g., between 2,500 and 5,000 ms on the firstupright-face trial) did not rule out changes in theinfants' region of interest. It 
is possible that they alternatedbetween two regions they were exploring(e.g., eyes and nose/mouth), but without beingsynchronized one with the others (e.g., some infantswent from the eyes to the nose/mouth, whereasothers did the opposite). Thus, Figure $4 a$ and $b$ pointout a common exploration rule, but do not tell usabout individual back-and-forth shifts. However, when the percentages for two regions are high at thesame time, we can hypothesize that the infants weremaking asynchronous back-and-forth shifts betweenthese two regions.

Shifts between facial features in each face orientation.

Figure $4 a$ and $b$ suggest that while the explorationof upright faces gave rise to back-andforthshifts between the eyes and the nose/mouth, theexploration of upside-down faces gave rise to backand-forth shifts between external features andother features. To further test this hypothesis, wecomputed the number of times the infant shiftedfrom one feature to another, or inversely, for eachtrial and infant. The features considered here werethe eyes versus the nose/mouth, the eyes versusexternal features, and the nose/mouth versus

the external features, as defined in Figure 3. An infant was said to change between two features whenshe or he looked at an area of interest for at least100 ms during a 200 msperiod, and to the other regionfor at least 100 ms during the subsequent $200 \mathrm{~ms}$ period. This criterion was used to take into accountshifts from one region to another, even when theinfants crossed another region on the way. With thiscriterion, situations where infants spent less than $180 \mathrm{~ms}$ in another region than the ones we were interestedin between the two previous regions wereconsidered as shifts between these two regions. This time was chosen because it is long enoughto do a saccade and short enough to discard situations where the infant did two saccades witha fixation in another region between the two saccades.The data for the number of shifts from oneregion to another and inversely were analyzed in a 2_6 _ 3 ANOVA with orientation (upright vs. upside-down), trial (1 vs. 2 vs. 3 vs. _3 vs. 2 vs. _1), and type of shift (eyes-nose/mouth vs. externalfeatures-eyes vs. external features-nose/mouth) aswithin-subject factors. The means for the number ofshifts in each experimental condition are presentedin Table 2.

The main effect of trial was significant, $F(5,100) 515.74$, po.0001; the number of shifts decreasedbetween the first and the last trials $(2.3,1.7,1.5,1.1,0.6$, and 0.8). No other effects or interactionswere significant. To further test the hypothesis ofdifferent types of shifts for upright and upside-downfaces, we performed linear comparisons to test both the effect of the type-of-shift factor in each orientationand the effect of the orientation factor for eachtype of shift. The main type-shift effect was nonsignificantfor upright faces, $F(2,40) 51.58$, but significantfor upside-down faces, $F(2,40) 55.66$, po.01.For upside-down faces, infants made fewer shiftsbetween the eyes and the nose/mouth region thanbetween the eyes and external features (0.9 vs. 1.5), $F(1,20) 59.04$, po.01, and between the nose/mouthand external features ( 0.9 vs. 1.2$), F(1,20) 55.46$, po.05. There was no difference between these lasttwo conditions, $F(1,20) 52.20$. Moreover, orientationhad a significant effect on the number of shifts betweenthe eyes and the nose/mouth (1.7 for uprightfaces vs. 0.9 for upside-down faces, $F(1,20) 56.11$, po.05, but not on the number of shifts between theeyes and external features, $F(1,20) 50.67$, or on the 


\begin{tabular}{|c|c|c|c|c|c|c|c|c|c|c|c|c|c|c|}
\hline \multirow{2}{*}{$\begin{array}{l}\text { Orientation } \\
\text { Trial }\end{array}$} & \multicolumn{7}{|c|}{ Upright } & \multicolumn{7}{|c|}{ Upside down } \\
\hline & 1 & 2 & 3 & -3 & -2 & -1 & Mean & 1 & 2 & 3 & -3 & -2 & -1 & Mean \\
\hline Eyes versus nose/mouth & 2.9 & 2.1 & 1.7 & 1.3 & 0.5 & 1.3 & 1.7 & 1.0 & 1.4 & 1.0 & 0.4 & 0.7 & 0.8 & 0.9 \\
\hline$S E$ & 0.8 & 0.4 & 0.5 & 0.6 & 0.2 & 0.5 & 0.8 & 0.3 & 0.3 & 0.3 & 0.1 & 0.2 & 0.4 & 0.3 \\
\hline External features versus eyes & 3.0 & 1.9 & 2.0 & 2.2 & 0.5 & 0.8 & 1.8 & 3.1 & 1.3 & 1.8 & 0.8 & 0.9 & 1.0 & 1.5 \\
\hline$S E$ & 1.0 & 0.5 & 0.4 & 0.7 & 0.2 & 0.3 & 0.8 & 0.7 & 0.4 & 0.6 & 0.2 & 0.3 & 0.4 & 0.5 \\
\hline External features versus nose/mouth & 1.9 & 1.3 & 1.4 & 0.8 & 0.5 & 0.5 & 1.1 & 1.7 & 2.4 & 1.1 & 1.0 & 0.6 & 0.2 & 1.2 \\
\hline$S E$ & 0.5 & 0.3 & 0.5 & 0.2 & 0.2 & 0.2 & 0.5 & 0.4 & 0.7 & 0.3 & 0.2 & 0.2 & 0.1 & 0.4 \\
\hline
\end{tabular}

number of shifts between the nose/mouth and externalfeatures, $F(1,20) 50.16$. Thus, the analysis of the number of shifts indicatedthat when the face was upright, infants moved asfrequently from one region to the other, no matterwhat regions were considered. When the face wasupside down, they went back and forth more oftenbetween external features and the eyes or the nose/mouth than between the eyes and the nose/mouth. The main effect of face inversion was a decrease inthe number of shifts between the two kinds of internalfeatures. Orientation did not affect the numberof shifts between external features and either theeyes or the nose/mouth.

\section{Conclusions}

The results of the present study showed that noquantitative difference was found for upright andupside-down faces during habituation (i.e., the infantsspent the same amount of time and needed thesame number of trials to habituate to upright andupside-down faces), whether measures were performedusing traditional recording methods or an

eye-tracking system. Nevertheless, the eye-movementrecordings showed that the infants did notexplore the faces in the same way under the twoorientations. They spent more time on internal features,mainly in the nose and mouth region, whenthe face was upright than when it was upside down. The time spent looking at the eyes was equivalent forthe two orientations, suggesting that face inversionmainly results in a transfer from nose/mouth lookingto external-feature exploration. The infantsconsidered as a group tended to all use the sameexploration strategy, at least for the first few trials ofhabituation, but that strategy depended on the orientationof the face. When the face was upright, theygenerally started by exploring the eyes for about $1 \mathrm{~s}$; next they looked at the nose/mouth, and then they alternated between periods of nose/mouth lookingand eye looking. When the face was upsidedown, the infants also tended to look at the eyesduring the first few seconds, but after that theypreferentially alternated between external featuresand internal features, whether the eyes or the noseand mouth. The analysis of back-and-forth gazeshifts between the features also showed that 4-month-old infants shifted to an equal extent betweenthe eyes, the nose/mouth, and external featureswhen the face was upright. When the face was upsidedown, however, they preferentially alternated between external and internal features, with thenumber of internal-feature shifts being lower than forthe upright face. Thus, the main effect of face inversionwas a decrease in internal-feature gaze shifts.

\section{General Discussion}

The present study indicated that 4-month-old infantsdo not explore upright and upsidedown faces in thesame way. These findings extend the previous researches,suggesting that 4-month-old infants processconfigural/invariant information (Cohen \&Cashon, 2001; 
Deruelle\& de Schonen, 1998; Turati et al., 2004), and that this ability is altered by inversion(Turati et al., 2004). The different ways in which theseinfants explored upright and upside-down faces aregood candidates to explain the behavior that underlinesthe extraction of such configural/invariantinformation. As inversion mainly influences the timethe infants spend on internal features such as thenose and mouth region, or the number of times the infants shift between this latter region and the eyeregion, both these behaviors may have to do withconfigural/invariant processing of the face. Thus, the present study highlights the interest of a qualitativeapproach to understand how infants processfaces. In our study as in the first experiment byTurati et al. (2004), there was no difference in thetime the infants took to habituate to upright andupside-down faces. The impact of inversion in faceprocessing was observable only via the more qualitativeapproach that consisted in considering whereand how the infants were looking at the face duringthe habituation phase.The way 4-month-old infants explored uprightand upside-down faces in our study sheds some newlight on the results reported by Cashon and Cohen(2003), notably the lack of an inversion effect forswitched faces at 4 months. Our results show thatinfants go back and forth many times between internaland external features when the faces are upsidedown, and that this kind of shifting is theprincipal one found for this orientation; thenumber of shifts between external features and either the eyes or the nose/mouth represented around75\% of all shifts between external features, the eyes,and the nose/mouth. For upright faces, this percentagewas only about $63 \%$. However, the totalnumber of shifts was quite similar in the twoorientations. Thus, if infants associate internal andexternal features via this shift behavior, one can expectthe same reaction for upright and upside-downfaces when the learned association is modified inswitched faces. This is what Cashon and Cohen(2003) reported for infants of the same age as in ourstudy. If this hypothesis is valid, then why does aninversion effect emerge at 7 months? The answer to

this question can probably be found by studying thedevelopment of exploration patterns during the $1^{\text {st }}$ year of life. The infants in our study spent approximately twothirds of their time exploring internal features, whichis quite a bit lower than in Hunnius and Geuze's(2004) study, where similar-age infants spent around $90 \%$ of their time in these regions. There are twomain explanations for this difference: the face usedby Hunnius and Geuze (2004) was moving, and itwas the mother's face. Facial movements may havedirected the infants' attention and gaze toward internalfeatures, which are the most important sourceof change in a dynamic face. Second, the fact that theface was highly familiar to the infants may have directedthem toward internal features. It has beenreported for adults that internal features play a moreimportant role in familiar than in unfamiliar facerecognition (e.g., Ellis, Shepherd, \& Davies, 1979;Young, Hay, McWeeny, Flude, \& Ellis, 1985). Thefamiliarity with the mother's face may haveprompted the infants to explore its internal featureslonger. The way infants explore a face, and in particularthe time they spend looking at internal features,thus clearly depends on a number of factors(face orientation, facial movement, familiarity). These factors no doubt also influence the efficiencyof face encoding. The weight of eyes in face processing by infantshas already been underlined in the literature (Batkyet al., 2000; Emery, 2000; see also Farroni, Johnson,Brockbank, \& Simon, 2000; Vecera\& Johnson, 1995).A particular role of the eyes also appears in ourstudy, whatever the orientation. The infants spend alarge part of their time exploring them (one third ofthe time they spend exploring the face) and, aboveall, they tend to go to this region first. Therefore, theeyes appear to be key information and the 
startingpoint of the exploration whatever the orientation ofthe face, i.e. whatever the exploration strategy the

infants adopt. A reason for this behavior may be thefact that the eyes are the most contrasted region of aface. Thus, they can capture the attention and looksof infants and allow them to locate the other lesscontrasted facial parts, relative to the position of theeyes. The relative position of the other facial regionsbeing altered by face inversion, the infants willchange their exploration strategy by altering betweeneyes and external features, whose relations(central intern feature versus extern part) are lessaltered by inversion.Beyond the theoretical question that was thepurpose of the present studyFface processing ininfantsFthis study clearly shows the interest of aqualitative approach, notably by the use of eyemovementrecording, in addition to traditionalquantitative methods. To know how the infant exploresthe world (i.e. where does she or he look, inwhich order does she or he explore different parts, does she or he explore the parts) may shed new lighton the cognitive processes that underline her or hisdeveloping abilities.

\section{References}

Bartrip, J., Morton, J., \& de Schonen, S. (2001). Responses tomother faces in 3-week to 5month-old infants. BritishJournal of Developmental Psychology, 19, $219-232$.

Batky, A., Baron-Cohen, S., Wheelwright, S., Connellan, J.,\&Ahluwalia, J. (2000). Is there an innate gaze module?Evidence from human neonates. Infant Behavior andDevelopment, 23, $223-229$.

Bertin, E., \& Bhatt, R. S. (2004).The Thatcher illusionand face processing in infancy. Developmental Science, 7,431-436.

Bushnell, I. W. R. (2001). Mother's face recognition innewborn infants: Learning and memory. Infant and ChildDevelopment, 10, 67- 74.

Bushnell, I. W. R., Sai, F., \& Mullin, J. T. (1989).Neonatalrecognition of the mother's face. British Journal ofDevelopmental Psychology, 7, 3- 15.

Cashon, C. H., \& Cohen, L. B. (2003). The construction, deconstruction, and reconstruction of infant face perception.In A. Slater \& O. Pascalis, The development of faceprocessing in infancy and early childhood (pp. 55 -68). NewYork: Nova Science Publishers.

Cohen, L. B. (1972). Attention getting and attention holdingprocesses of infant visual preferences. Child Development,43, $869-879$.

Cohen, L. B., \&Cashon, C. H. (2001). Do 7-month-oldinfants process independent features or facial configurations? Infant and Child Development, 10, 83-93.

Deruelle, C., \& de Schonen, S. (1998). Do the right and lefthemispheres attend to the same visuospatial informationwithin a face in infancy? Developmental Neuropsychology,14, 535 554. 
Diamond, R., \& Carey, S. (1986). Why faces are not special:An effect of expertise. Journal of Experimental Psychology:General, 115, $107-117$.

Ellis, H. D., Shepherd, J. W., \& Davies, G. M. (1979).Identification of familiar and unfamiliar faces frominternal and external features: Some implications for theories of face recognition. Perception, 8, $431-439$.

Emery, N. J. (2000). The eyes have it: The neuroethology,function and evolution of social gaze. Neuroscience andBiobehavioral Reviews, 24, 581- 604.

Farah, M. J., Wilson, K. D., Drain, M., \& Tanaka, J. N.(1998).What is "special" about face perception? PsychologicalReview, 105, $482-498$.

Farroni, T., Johnson, M. H., Brockbank, M., \& Simon, F.(2000). Infants' use of gaze direction to cue attention:The importance of perceived motion. Visual Cognition, 7 ,

$705-718$.

Field, T. M., Cohen, D., Garcia, R., \& Greenberg, R. (1984).Mother - stranger face discrimination by the newborn.Infant Behavior and Development, 7, $19-25$.

Haith, M. M. (2004). Progress and standardization in eye movement work with human infants. Infancy, 6, 257-265.

Hunnius, S., \&Geuze, R. H. (2004). Developmentalchanges in visual scanning of dynamic faces and abstractstimuli in infants: A longitudinal study. Infancy, 6,231 - 255.

Johnson, S. C., Slemmer, J. A., \&Amso, D. (2004). Whereinfants look determines how they see: Eye movementsand object perception performance in 3-month-olds.Infancy, 6, 185 207.

Langlois, J. H., Roggman, L. A., Casey, R. J., Ritter, J. M.,Rieser-Danner, L. A., \& Jenkins, V. Y. (1987). Infantpreferences for attractive faces: Rudiments of a stereotype?Developmental Psychology, 23, $363-369$.

Maurer, D., Le Grand, R., \&Mondloch, C. J. (2002). Themany faces of configural processing. Trends in CognitiveSciences, 6, 255- 260.

Pascalis, O., de Haan, M., Nelson, C. A., \& de Schonen, S.(1998). Long-term recognition memory for faces assessed by visual paired comparison in 3- and6-month-old infants. Journal of Experimental Psychology:Learning, Memory, and Cognition, 24, 249 - 260.

Pascalis, O., \& de Schonen, S. (1994). Recognition memoryin 3- to 4-day-old human infants. NeuroReport, 5,1721 - 1724.

Pascalis, O., de Schonen, S., Morton, J., Deruelle, C., \&Fabre-Grenet, M. (1995). Mother's face recognition in neonates: A replication and an extension. Infant Behavior and Development, 18, $79-85$. 
Quinn, P. C., Yahr, J., Kuhn, A., Slater, A. M., \&Pascalis, O.(2002). Representation of the gender of human facesby infants: A preference for female. Perception, 31,1109-1121.

SaI", F., \& Bushnell, I.W. R. (1988).The perception of faces indifferent poses by 1-month-olds. British Journal of DevelopmentalPsychology, 6, $35-41$.

Salapatek, P. (1975). Pattern perception in early infancy. InL. B. Cohen \& P. Salapatek (Eds.), Infant perception: Fromsensation to cognition (pp. $144-248)$. New York: AcademicPress.

Schwarzer, G., \&Zauner, N. (2003). Face processing in8-month-old infants: Evidence for configural and analyticalprocessing. Vision Research, 43, 2783- 2793.

Simion, F., Farroni, T., Macchi Cassia, V., Turati, C., \&DallaBarba, B. (2002).Newborns' local processing in schematicfacelike configurations. British Journal of DevelopmentalPsychology, $20,465-478$.

Slater, A., Quinn, P. C., Hayes, R., \& Brown, E. (2000).The role of facial orientation in newborn infants' preferencefor attractive faces. Developmental Psychology, 3,181 - 185.

Slater, A., Von der Schulenburg, C., Brown, E., Badenoch,M., Butterworth, G., Parsons, S., \& Samuels, C. (1998).Newborn infants prefer attractive faces. Infant Behaviorand Development, 21, $345-354$.

Thompson, L. A., Madrid, V., Westbrook, S., \& Johnston, V.(2001). Infants attend to secondorder relationalproperties of faces. Psychonomic Bulletin and Review, 8,769 - 777.

Turati, C., Sangrigoli, S., Ruel, J., \& de Schonen, S. (2004). Evidence of the face inversion effect in 4-month-old infants.Infancy, 6 (pp. $275-297$ ).

Turati, C., \&Simion, F. (2002).Newborns' recognitionof changing and unchanging aspects of schematicfaces. Journal of Experimental Child Psychology, 83, 239 261.

Valentine, T. (1988). Upside-down faces: A review of theeffect of inversion upon face recognition. British Journalof Psychology, 79, 471 - 491.

Vecera, S. P., \& Johnson, M. H. (1995). Gaze detection andthe cortical processing of faces: Evidence from infantsand adults. Visual Cognition, 2, 59-87.

Walton, G. E., Bower, N. J. A., \& Bower, T. G. R. (1992). Recognition of familiar faces by newborns. InfantBehavior and Development, 15, 265- 269.

Yin, R. K. (1969).Looking at upside-down faces. Journal ofExperimental Psychology, 81, 141 145.

Young, A. W., Hay, D. C., McWeeny, K. H., Flude, B. M., \&Ellis, A. W. (1985). Matching familiar and unfamiliarfaces on internal and external features. Perception, 14,737 - 746. 
